\title{
Bacteriophage-host interactions and resistance mechanisms, analysis of the conjugative bacteriophage resistance plasmid pNP40
}

\author{
C Hill 1,2, P Garvey 1, GF Fitzgerald 1,2 \\ 1 Department of Microbiology; \\ 2 National Food Biotechnology Centre, University College, Cork, Ireland
}

\begin{abstract}
Summary - Research into bacteriophage and bacteriophage resistance in the lactic acid bacteria has moved into a new and exciting dimension in recent years. Mechanisms such as adsorption inhibition, restriction and modification, and abortive infection which have been described phenotypically over the past decade are now being subjected to molecular analysis, and this has led to a better understanding of the nature and variety of resistance systems employed by lactic acid bacteria to combat phage attack. In addition, analysis of different bacteriophage has increased our knowledge of these ubiquitous particles to the point where it is possible to construct novel phage resistances based on the phage genome. This review will briefly outline the recent progress in the molecular analysis of bacteriophagehost interactions, bacteriophage resistance and counter resistance, and the construction of novel resistance mechanisms. In particular, recent evidence regarding the mechanisms of resistance employed by the conjugative plasmid pNP40 will be described in some detail. In addition, an instance will be described in which pNP40 has been used in the construction of phage resistant starters which have been successfully exploited by the dairy industry.
\end{abstract}

\section{bacteriophage / resistance / Lactococcus}

\begin{abstract}
Résumé - Bactériophages et mécanismes de résistance aux bactériophages des bactéries lactiques. Les recherches concernant les bactériophages et les mécanismes de résistance aux bactériophages des bactéries lactiques ont connu un essor certain ces 10 dernières années. Les mécanismes de résistance tels que l'inhibition d'adsorption, la restriction-modification et l'infection abortive qui ont été décrits phénotypiquement font maintenant l'objet d'une analyse moléculaire, ce qui permet une meilleure compréhension de la nature et de la variété des systèmes de résistance utilisés par les bactéries lactiques pour combattre les attaques phagiques. De plus, l'analyse de différents bactériophages permet d'envisager de nouveaux mécanismes de résistance à partir de la connaissance du génome des phages. Dans cet article, nous soulignerons brièvement les progrès récents dans l'analyse moléculaire des interactions bactériophage-hôte, de la résistance et de la capacité des phages à s'adapter pour échapper aux mécanismes de résistance et de la construction de nouveaux mécanismes de résistance. Nous détaillerons plus particulièrement les mécanismes de résistance portés par le plasmide conjugatif pNP40. Un exemple dans lequel pNP40 a été utilisé pour construire des souches résistantes aux phages et testées avec succès par l'industrie laitière sera décrit.
\end{abstract}




\section{INTRODUCTION}

Bacteriophage (phage) are a major source of disruption in dairy fermentations. Although many strategies have been employed to minimise disruption due to bacteriophage these ubiquitous particles remain a significant problem. This has provided the impetus for many research laboratories to investigate phagehost interactions, with a particular emphasis on the molecular basis of phage resistance in these industrially important cultures.

It has long been known that certain starter cultures are naturally phage insensitive. The development of sophisticated genetic and molecular technologies for lactococci has established that these bacteria can harbour a battery of resistance mechanisms which are usually, though not always, plasmidencoded. Numerous lactococcal phage resistance plasmids have been identified, several of which were found to be conjugative (reviewed in Hill, 1993; Klaenhammer and Fitzgerald, 1994). Extensive studies on the mechanisms of phage resistance have enabled their classification into three categories: adsorption inhibition; restriction/modification (R/M); and abortive infection (Abi). In this report, we will briefly review the recent progress in the molecular analysis of bacteriophage-host interactions, bacteriophage resistance and counter resistance, and the construction of novel resistance mechanisms. In particular, recent evidence regarding the mechanisms of resistance employed by the conjugative plasmid pNP40 will be described in some detail.

\section{BACTERIOPHAGE}

\section{Bacteriophage lytic cycle}

In order to fully appreciate the mechanisms of resistance employed by the lactococci, it is necessary to briefly describe the interac- tions between phage and host cell. The most complete study of early phage infection in lactococci has been conducted by Geller and co-workers on the prolate headed phage $ø c 2$ (Valyasevi et al, 1991, 1994; Geller et al, 1993; Monteville et al, 1994). The initial interaction with the sensitive cell involves attachment of the phage to carbohydrate moieties in the cell wall. The initial adsorption stage was found to be reversible following the addition of L-rhamnose suggesting a rhamnosyl compound as the phage receptor but this binding becomes irreversible over time as the infection continues. The phage then appears to interact with a specific membrane-located protein, PIP (phage infection protein), as membranes purified from derivatives deficient in PIP failed to adsorb phage (Valyasevi et al, 1991). The involvement of PIP or the $32 \mathrm{kDa}$ protein in translocation of the phage DNA across the membrane remains to be established.

Although carbohydrate cell wall components, in particular L-rhamnose, have been implicated as receptors for many other phages (Keogh and Pettinghill, 1983; Valyasevi et al, 1990; Schafer et al, 1991), the involvement of the cell membrane is less certain. In fact, Valyasevi et al (1991) have shown that øsk 1 is not inactivated by cell membranes isolated from $L$ lactis ssp lactis $\mathrm{C} 2$, indicating that different lactococcal phages have alternative routes for adsorption and DNA injection into the host. This was also demonstrated by the pattern of adsorption of lactococcal phages to their hosts; Budde-Niekiel and Teuber (1987) and Schafer et al (1991) both observed that adsorption could occur either to specific locations or uniformly over the entire cell surface.

Several studies have investigated the intracellular development of phage during the lytic cycle. After phage DNA injection, shut-down of the host metabolism is mediated by early phage genes and phage repli- 
cation is initiated. Powell et al (1992) demonstrated that degradation of host DNA began within 6 min of infection and that the breakdown products were incorporated into progeny øc6A DNA. Quantitative DNA hybridizations indicated that synthesis of phage DNA began within 6 min of infection and continued at an approximately constant rate throughout the latent period. $ø 31$ was shown by Hill et al (1991a) to replicate by a concatemeric intermediate and evidence was supplied to suggest a similar mechanism for øc6A (Powell et al, 1992).

Transcription studies have been conducted on a number of phage, including the temperate phage øTuc2009 (Casey, 1991), and the lytic øc2 (Beresford et al, 1993) and øsk1 (Chandry et al, 1994). In all cases it was demonstrated that transcription was temporally regulated. In the cases of øTuc2009 and øc2, transcription could be detected in two distinct stages, beginning with early gene expression and progressing to the distal portion of the genome where the late genes appeared to be clustered. Transcription of øsk1, however, followed three stages: early (2-5 min following infection); middle (7-10 min following infection); and late (at least $15 \mathrm{~min}$ following infection). Latent periods have been found to vary considerably between 9 and $139 \mathrm{~min}$ for different lactococcal phages and burst sizes of up to 250 particles per cell have been recorded; however, these figures varied depending on the temperature of infection and in some instances, on the propagating host (Keogh, 1973; Sing and Klaenhammer, 1990).

\section{Molecular analysis of phage genomes}

Recent years have seen the first reports of the sequencing of the entire genome of the lactococcal prolate-headed phage bIL67 (Schouler et al, 1994) and other lactococcal phages, eg, øTuc2009 (van de Guchte et al, 1993) and øR1-t (Nauta et al, 1993). These studies have provided valuable information on the organization of phage genomes. Thirty-seven ORFs were identified on the genome of øblL67 which were organized into two clusters. One cluster comprised 17 ORFs, one of which showed features in common with a DNA polymerase and another whose deduced amino acid sequence demonstrated significant homology to a recombinase. Late genes such as the lysin gene, a minor tail protein, a putative holin and a terminase subunit were identified in the second gene cluster. The two gene clusters were divergently transcribed and terminated at the phage cos site. Interestingly, two sub-clusters comprising ORFs 4, 5 and 6 and ORFs 12 and 13 were flanked by repeated sequences of $25 \mathrm{bp}$ and $31 \mathrm{bp}$, respectively. The authors suggested that these features may be involved in Campbell-type recombination and exchange of phage modules. This information may explain the highly recombinogenic properties exhibited by some phages. Sequence of the temperate lactococcal phages $ø$ R1-t (Nauta et al, 1993) and øTuc2009 (van de Guchte et al, 1993) have demonstrated the widespread presence of translationally coupled genes confirming the compact nature of phage genomes.

\section{BACTERIOPHAGE RESISTANCE}

\section{Adsorption inhibition}

Adsorption inhibition describes the insensitivity which results if the phage receptor is absent, altered or masked. Masking of the receptor can in some instances be reversed by removal of the masking material, whereas phage adsorption ability cannot be restored to a strain where a mutation is responsible for the resistance phenotype. Plasmids encoding adsorption inhibition have been 
isolated from several phage insensitive strains.

Perhaps the most extensively studied plasmid-encoded adsorption inhibition mechanism is that determined by pSK112, a 34 MDa plasmid from $L$ lactis ssp lactis SK110 (Sijtsma et al, 1990a). Native SK110 failed to adsorb phage whereas derivatives cured of pSK112 adsorbed phage normally. Alkali treatment of pSK112-containing hosts also permitted the phage adsorption process to proceed normally. It was proposed that phage resistance was mediated through shielding of the phage receptor by a galactose-containing layer since material recovered following the alkali treatment was identified as a galactose-containing lipoteichoic acid or a part thereof (Sijtsma et al, 1990b). Plasmid pCl528, an adsorption blocking plasmid identified by Costello (1988) mediates resistance by a mechanism similar to that of pSK112. Electron microscopy demonstrated the presence of an irregularly distributed substance surrounding the cell surface (Lucey et al, 1992). As was the case with pSK112, dilute alkali washing of resistant cells restored full sensitivity to phage. Gas liquid chromotography analysis revealed elevated levels of galactose and rhamnose in cell wall samples of resistant strains.

The precise nature of the genetic determinants responsible for adsorption inhibition has not been established. Despite generating overlapping subclones of the entire pCl528 genome, Lucey (1992) was unable to achieve expression of the phage resistance phenotype, suggesting that a large contiguous fragment or more than one locus was required. This is an area deserving of continued investigation.

\section{Restriction and modification (R/M)}

R/M systems are composed of a highly sequence-specific endonuclease and a com- panion methylase which modifies a nucleotide within the same recognition site, thereby protecting resident DNA from digestion. $\mathrm{R} / \mathrm{M}$ systems are widely distributed in lactococci, and many of these are encoded on plasmids.

The determinants responsible for a number of plasmid-encoded R/M systems have been cloned, and in a few instances, sequenced (Hill, 1993). These include the Lla 1 operon encoded by the conjugal plasmid pTR2030. Examination of the methylase gene predicted a protein which contained the 10 and 15 aa consensus sequences common to all type II adenine methylases (Hill et al, 1991b). Unusually, both consensus sequences appeared twice, suggesting that the protein contains two methylase domains and acts as a covalently-linked dimer modifying the complementary strands of an assymetric recognition site (Klaenhammer et al, 1991). Four additional ORFs were found to be located on the same transcriptional unit downstream of the methylase gene, and frame-shift mutations at selected EcoRI sites present within these ORFs suggested the involvement of three of these in the expression of the Llal restriction activity (O' Sullivan et al, 1995). In addition, a small ORF was identified upstream which exhibited homology to a class of regulatory proteins for type II R/M systems. This type of gene arrangement is unusual for type II R/M systems, and is the only one of its kind demonstrated to date in lactococci.

Although the majority of lactococcal R/M systems studied to date have been plasmid-encoded, this is not always the case. Davis et al (1993) reported the first isolation of lactococcal methylase determinants from chromosomal sources. Two distinct methylases were cloned from the chromosome of L lactis ssp cremoris UC505 and expressed in E coli. Selection of clones was based on their ability to fully protect the DNA from cleavage by the cognate ScrFI endonu- 
clease. The two methylases reside on adjacent ECORI fragments on the UC503 chromosome and DNA sequence analysis of the intervening region revealed an additional ORF which encodes the $\mathrm{Scr} F \mathrm{~F}$ restriction endonuclease (Garvey et al, 1995). Recently, the sequence of a further lactococcal R/M operon has been determined (Moineau et al, 1995). Llall from L lactis ssp cremoris $\mathrm{DCH}-4$, which recognizes the sequence GATC, is also composed of three open reading frames, two involved in methylation and one in restriction. The genes possess strong homologies with the Dpnll system.

A fourth lactococcal R/M system designated $L /$ alli, encoded by pJW563 from $L$ lactis ssp lactis W56 has been cloned (Josephsen and Vogensen, 1989) and sequenced (Nyengaard et al, 1993), In this instance, the methylase and restriction endonuclease are encoded by single open reading frames which are divergently transcribed (Nyengaard et al, 1993). Although only four lactococcal $\mathrm{R} / \mathrm{M}$ systems have been analysed to this level, the diversity of genetic organization is striking.

\section{Abortive infection (Abi)}

Abortive infection describes any phage resistance mechanism which interferes in intracellular phage development (Duckworth et al, 1981). Therefore, mechanisms which hinder phage genome replication, transcription/translation, phage packaging or cell lysis/phage release are all grouped under this term. Abortive infections are phenotypically characterized either by the absence of plaques or by reduced EOPs and reduced plaque sizes, which are most probably a reflection of lower numbers of productive infections and limited release of phage progeny (Sing and Klaenhammer, 1990). One of the most distinctive aspects of Abi-mediated resistance is that cell survival is low, possibly because corruption of host functions and host DNA degradation have already been initiated prior to operation of the abortive mechanism.

The genetic determinants for several lactococcal Abi mechanisms have been cloned and five have been analysed at the DNA sequence level, abiA (formerly $h s p$ ) from pTR2030 (Hill et al, 1990b) and from pCl829 (Coffey et al, 1991); abiB (formerly abi416) from total cell DNA isolated from $L$ lactis ssp lactis 416 (Cluzel et al, 1991); abiC from pTN20 (Durmaz et al, 1992); abiD from pBF61 (Mc Landsborough et al, 1995); and abiD 1 from plL105 (Anba et al, 1995). It has been noted that the products of the $a b i D$ and abiD1 determinants are related, although the level of identity is low (28\%).

The effect of $A b i A$ on lactococcal phage DNA replication was investigated in both $\mathrm{AbiA}^{+}$and AbiA- cells (Hill et al, 1991a). No phage DNA replication was observed in cells expressing AbiA, although an intact copy of the injected phage genome could be detected in the host cytoplasm. The Abi mechanisms encoded by pBU1-8 (Geis et al, 1992) and pTN20 (AbiC) have been shown to differ from that encoded by pTR2030 in that phage DNA replication did take place; although, in the case of pBU1-8, the rate of replication was considerably reduced. Intracellular øP008 DNA concentration increased slowly over a 5 -h period following infection of a pBU1-8-containing host whereas only $60 \mathrm{~min}$ were required before high phage DNA concentrations were obtained within a sensitive host (Geis et al, 1992). In the case of AbiC (Durmaz et al, 1992), øp2 DNA replication was not visibly inhibited.

Further attempts were made to elucidate the mechanisms involved in abortive infection as encoded by abiC and pBU1-8. No transcription of phage DNA was detected in $ø$ P008-infected cells containing pBU1-8 by Geis et al (1992) suggesting a block at 
this stage. Using monoclonal antibodies directed against the capsid protein of the small isometric phage øu136, Moineau et al (1992) established that production of this protein was reduced by $50 \%$ in cells containing $\mathrm{AbiC}$, indicating that the target for the mechanism possibly involved the phage transcription, translation or packaging processes. These results confirm that not all Abi systems operate on a single target and that the term describes a variety of late-acting phage resistance mechanisms. This highlights the potential for exploitation of multiple Abi systems to inhibit phage at sequential steps in the lytic cycle in order to provide higher levels of phage resistance. Interestingly, a number of phage mutants capable of overcoming the AbiD1 mechanism have recently been analysed at the sequence level, and a phage operon involved in sensitivity to AbiD1 has been identified (Bidnenko et al, 1995).

\section{CONSTRUCTION OF PHAGE RESISTANT STARTER STRAINS}

Following the discovery that the phage resistance plasmid pNP40 was conjugative, McKay and Baldwin (1984) proposed a conjugal strategy for the construction of food-grade bacteriophage resistant strains for the dairy industry. This approach was subsequently employed by Sanders et al (1986) in the construction of derivatives of commercial starter cultures containing pTR2030 and proved to be the first example in which the genetic manipulation of strains yielded a practical application. The novel strains have improved phage resistance characteristics and have been exploited successfully under industrial conditions. This approach has also been used successfully by Kelly et al (1990) and Harrington and Hill (1991) in the introduction of $\mathrm{pCl} 750$ and $\mathrm{pCl} 528$, and pNP40, respectively into commercial starter strains.
The advantage of this strategy is that it is non-recombinant and exploits a method of gene transfer used naturally by lactococci, thus yielding food-grade starters. All of these strains have been used successfully in industry but, in the case of pTR2030 transconjugants, prolonged use under industrial conditions resulted in the detection of several phage which were capable of overcoming the pTR2030-encoded R/M and Abi phage resistance mechanisms. One such phage, $\varnothing 50$, was found by $\mathrm{Hill}$ et al (1991b) to have protected itself against restriction by effectively cloning an active portion of the Llal methylase determinant. This enabled the phage to self-modify its DNA and remain insensitive to the action of Llal.

More recently another phage, øul37, has evolved in response to pressure exerted by the activity of the AbiC mechanism on pTRK99 (Moineau et al, 1994). Restriction mapping indicated that this phage was a derivative of øul36 (an AbiC sensitive phage) which had acquired a large DNA fragment from the chromosome of the resistant transconjugants. Despite extensive homology at the genomic level, øul37 differed considerably from øul36 having a longer tail, a different base plate and a different origin of replication. The DNA acquisition by øul37 was specific and reproducible in that all mutant phages isolated contained the same discrete fragment of DNA. When the chromosomal DNA implicated in the formation of øul37 was interrupted by site-specific integration, the reemergence of øul37 during subsequent infections with øul36 was prevented. This example shows the potential of the host to act as a reservoir of new genetic material for phage evolution in industrial fermentations and also demonstrated how molecular technology can be used not only to establish the origin of newly acquired DNA but also to prevent the re-occurrence of the recombination event. 


\section{NOVEL PHAGE RESISTANCE MECHANISMS}

In recent years, an increased knowledge of the molecular biology of lactococcal phages has permitted the development of phage resistant strains by two novel methods. The first strategy exploited bacteriophage DNA as a source of new phage resistance determinants (Hill et al, 1990a). It was shown that a $1.4 \mathrm{~kb}$ DNA fragment from $\varnothing 50$ conferred resistance on a previously sensitive strain. The resistant phenotype, which is reminiscent of Abi-like mechanisms, was designated per (phage encoded resistance). Sequence analysis revealed a 500 bp region rich in secondary structure which contained the $ø 50$ origin of replication. It is likely that the presence of the per locus inhibited $ø 50$ DNA replication by competing for essential phage replication factors.

An alternative strategy for generating phage resistant strains was devised by Kim and Batt (1991) and involved the use of antisense mRNA. Cloning of a phage gene of unknown function (gp51C) in the antisense orientation relative to a strong promoter, resulted in a $>99 \%$ decrease in EOP and a reduced plaque size. Subsequently, Chung et al (1992) cloned the major capsid protein (MCP) of $ø \mathrm{~F} 4-1$ in the antisense orientation, but this resulted in only a slight decrease in EOP. These data suggest that the usefulness of this method is best confined to situations involving ORFs with a low level of transcription/translation since antisense mRNA directed against these appears to be more effective than when it is directed against genes which are transcribed in relatively high amounts.

\section{THE CONJUGATIVE RESISTANCE PLASMID PNP40}

The conjugative lactococcal plasmid pNP40 was the first plasmid to be identified as encoding Abi (McKay and Baldwin, 1984). It confers complete resistance to both prolate and isometric-headed phage as manifested by the absence of plaques on a lawn of cells containing pNP40. Recent analysis using a combination of shotgun cloning strategies and an analysis of the phage resistance phenotypes has revealed that at least three independent mechanisms are encoded by pNP40 (Garvey, 1995). The plasmid encodes two distinct $\mathrm{Abi}$ mechanisms, AbiE and $\mathrm{AbiF}$, and in addition confers insensitivity by a novel mechanism which interferes with phage DNA injection.

\section{AbiE}

pPG01, a recombinant plasmid containing a $6.0 \mathrm{~kb}$ Ncol fragment from pNP40, conferred partial resistance to $ø 712\left(E O P=10^{-4}\right)$. No resistance was evident against $ø c 2$. Deletion analysis identified a $2.5 \mathrm{~kb} \mathrm{Scal} / \mathrm{Hpal}$ fragment as the smallest fragment capable of encoding insensitivity. The phage resistance phenotype associated with the recombinant plasmid conforms to the definition of abortive infection and was designated AbiE. Phage adsorbed to the host normally, their DNA was injected and the host cells were killed. Phage DNA replication occurred but no evidence of packaging of phage DNA or phage release were observed. In fact, $85 \%$ of infected cells did not produce progeny phage and the burst size in the remainder was reduced eight-fold. These observations suggest a late target of inhibition as there is little effect on phage DNA replication. Possible mechanisms include interference in transcription/translation processes, as in the case of AbiC (Moineau et al, 1992), or defects in packaging or release of phage particles.

The genetic organization of $\mathrm{AbiE}$ is striking in that it appears that two overlapping ORFs encode the abortive infection phenotype (Garvey et al, 1995). This is a unique 
arrangement among the lactococcal abortive infection genes sequenced to date, all of which involve a single ORF. Overlapping of genes may induce translational coupling which is believed to direct the stoichiometric synthesis of proteins by making translation of the second gene dependent on that of the first, thus ensuring proportional production of proteins. The absence of an identifiable promoter for abiEb substantiates the possibility of co-transcription for these ORFs.

\section{AbiF}

A second recombinant plasmid, pCG1, harbouring a $5.6 \mathrm{~kb}$ insert, conferred partial resistance to both $\varnothing c 2$ and $\varnothing 712$. The resistance encoded by pCG1 bears the phenotypic hallmarks of an abortive infection-type mechanism in that the EOP and plaque size were reduced for both prolate- and isometric-headed phages. Phage adsorbed normally to strains harbouring pCG1, the phage DNA was internalized but replication was significantly retarded. The presence of $\mathrm{pCG} 1$ in the cell resulted in a considerable reduction in the number of phage progeny produced by infected PG020 cells, and the failure of some of the cells $(20-23 \%)$ to give rise to any progeny.

The Abi locus was identified within pCG1 through a combination of deletion analysis and insertional inactivation. Resistance was associated with a single ORF which has the capacity to encode a protein of 342 aa with a predicted molecular mass of $41.2 \mathrm{kDa}$ (Garvey et al, 1995). Sequence comparison suggests that the protein product belongs to a recently identified family of $\mathrm{Abi}$ proteins, those encoded by abiD (McLandsborough et al, 1995) and abiD1 (Anba et al, 1995). The predicted product of the pCG1 gene is highly related to that encoded by abiD1 ( $47 \%$ identity, along the length of the protein), and also bears some relatedness with the recently identified $a b i D$ gene prod- uct ( $26 \%$ identity). This is similar to the degree of relatedness between $a b i D$ and abiD1 (28\% identity; Anba et al, 1995). An alignment of the three related gene products reveals a number of highly conserved regions, with $18 \%$ of residues common to all three proteins. The GC content of abiF is $26 \%$ which is exceptionally low for lactococcal genes (average GC content 37\%). However, low GC contents appear to be a feature of lactococcal abi genes. A similar feature was observed in the low GC contents of abiEi and abiEii (29\% in both instances). This is also true of $a b i A, a b i B$, $a b i C, a b i D$ and $a b i D 1$ all of which have GC contents of approximately $27 \%$. It is not known if these atypical GC contents reflect the function performed by abi genes or whether it reflects their origin.

\section{A role for RecA in phage reșistance?}

Sequence analysis of the $3.3 \mathrm{~kb}$ region located between the determinants for AbiE and $\mathrm{AbiF}$ revealed the presence of two ORFs which were found to be transcribed in the reverse orientation relative to the phage resistance genes (fig 1). One of these ORFs was found to code for a recA homologue based on DNA sequence homology. This plasmid-encoded recA was designated recA $A_{L P}$ (for lactococcal plasmid) to distinguish it from the chromosomally-located lactococcal recA (rec $A_{L}$ ) identified by Duwat et al (1992). In complementation studies, Rec $A_{L P}$ failed to complement the RecA deficient strain L lactis ssp lactis VEL1122, as assessed by resistance to mitomycin $C$. It is possible, however, that functions of RecA, other than co-protease activity, are provided by this protein as the lactococcal RecA was shown by Duwat and Gruss (1994) to have a role in the management of other forms of stress in the cell.

The presence of a recA homologue in close proximity to two abortive infection 




Fig 1. Genetic organization of a region of pNP40 involved in phage resistance, indicating the location and orientation of open reading frames. Putative promoters are represented by the letter $P$, and their orientation is indicated by an arrow. Potential terminators are represented by the letter T.

Organisation génétique d'une région de pNP40 impliquée dans la résistance aux phages, indiquant la localisation et l'orientation des phases ouvertes de lecture. Les promoteurs potentiels sont représentés par la lettre $P$ et leur orientation indiquée par une flèche. Les terminateurs potentiels sont représentés par la lettre $t$.

determinants prompted us to investigate whether RecA may play a role in phage resistance in lactococci. Studies in which the various clones were introduced to $R e c A_{L}$-deficient strains demonstrated that the chromosomally-encoded $\operatorname{Rec} A_{L}$ was essential for full phenotypic expression of AbiF. Conversely, AbiE functioned independently of RecA. Interestingly, while Rec $A_{L}$ has a role in phage resistance, $R_{e c} A_{L P}$ does not supply this function when introduced into the $R e c A_{L}$-deficient host. It is noteworthy that in Vibrio cholera, RecA has been implicated in bacteriophage resistance where it was discovered that the sulA gene product, which contributes to an abortive infection mechanism, is cleaved by RecA (Biswas et al,1992). Of added interest is the suggestion that LexA may be involved in regulation of an abortive infection gene in Escherichia coli (Gupta and McCorquodale, 1988).

The predicted product of the second ORF located between the two abi genes, ORFU, displayed $22 \%$ identity and up to $62 \%$ conservation with UmuC-like proteins of $E$ coli and Salmonella typhimurium. UmuC is one of two proteins encoded by the $u m u D C$ operon which forms part of the SOS regulon. The $u m u D C$ operon is a component of the error-prone DNA repair pathway in $E$ coli and $S$ typhimurium. Thus, ORFU may represent a lactococcal analogue on the conjugative plasmid pNP40.

\section{A novel phage injection blocking mechanism encoded by pNP4O}

pNP40 is unique in that it is the only lactococcal phage resistance plasmid isolated to date on which two distinct Abi mechanisms have been identified. Since AbiE does not have any effect on the prolate headed phage $ø c 2$, the resistance encoded by pNP40 against øc2 cannot be accounted for through the action of AbiF alone. For example, when cells containing pNP40 are infected with øc2 little cell death results. If the resistance mechanisms relied solely on Abi-type systems a high level of cell death would be predicted. These experiments indicated the presence of an additional earlyacting mechanism on pNP40 against $ø c 2$. Two early-acting resistance mechanisms have been identified in lactococci: adsorption inhibition and $\mathrm{R} / \mathrm{M}$. Adsorption assays using $L$ lactis spp lactis MG1614 and MG1614 containing pNP40 revealed that over $98 \%$ of øc2 particles adsorbed to both hosts, indicating that the putative early-acting mechanism did not operate by classical adsorption blocking. In addition, a series of phage propagation experiments, conducted in different hosts, also confirmed that R/M was not involved in the phage resistance phenotype exhibited by pNP40 containing hosts. In light of these results, we speculated that a novel resistance mechanism is active in resistant cells, and that this mechanism acts by preventing phage DNA injection. This theory is supported by several lines of evidence:

i) Phage øc2 particles adsorb to sensitive and resistant (containing pNP40) hosts 
with equal efficiency, and electron microscopy showed that this attachment occurred in the normal tail-first orientation. This process was initially reversible by the addition of L-rhamnose and, over time, became irreversible, demonstrating that the adsorption function of the host cell wall was not impaired and that resistance occurred at a subsequent step in the infection process.

ii) Only $10 \%$ of cells died as a result of infection, suggesting that this mechanism must operate prior to corruption of host functions or DNA degradation by the infecting phage.

iii) Internalization of the genomes of the infecting phage was delayed as evidenced by the inability to detect phage DNA within infected pNP40-containing cells until at least $30 \mathrm{~min}$ following infection as opposed to 5 min in the case of a sensitive host.

iv) When phage DNA was introduced to the resistant host a significant increase in $\mathrm{ECOI}$ (efficiency of centre of infection; a measure of the number of infected cells which release progeny phage) was detected following circumvention of the early stages of infection, by electroporation of phage DNA into resistant hosts, also supporting the view that the early-acting pNP40-encoded resistance acts at the level of phage DNA penetration into the cell.

It is likely, based on the results presented here, that it is an alteration at the level of the cell membrane that prevents phage DNA injection into the pNP40-containing host. It is possible that the compound encoded by pNP40 could prevent production, activity or the correct localization of specific receptors for øc2. The early-acting pNP40-encoded resistance mechanism is not active against the small isometric-headed phage $₫ 712$. This supports evidence by Valyasevi et al (1991) that all phages do not have the same infection requirements with respect to the host cell membrane.

\section{CONCLUSIONS}

It seems likely therefore, that at least four categories of phage resistance are operative in lactococci: adsorption blocking, R/M, Abi and a mechanism which inhibits phage DNA injection. pNP40 is a unique plasmid in at least two respects; it encodes two independent Abi mechanisms (one of which requires two ORFs), and it also encodes the first example of a novel mechanism which blocks phage DNA injection of specific phages. These features, combined with the conjugative nature of the plasmid, and the fact that it also encoded a nisin resistance gene, make pNP40 an ideal candidate for strain construction strategies. These properties have been exploited to provide the lactic butter industry with a phage resistant derivative of $L$ lactis subsp diacetylactis $425 \mathrm{~A}$, a vital component of the starter mix used in this industrially important process (Harrington and Hill, 1992). The transconjugant has performed well in industrial production under conditions in which the parental strain has failed due to phage attack.

The ongoing research in the molecular characterization of phage and phage resistance has contributed both to our understanding of the interactions between these old foes, and has also impacted the dairy industry which uses the improved strains arising from these fundamental studies. The prospect of constructing strains employing multiple, complementary, phage resistance systems is clearly within our capabilities, and is limited only by industry and consumer reaction to the prospect of using recombinant cultures in a medium destined for human consumption. The removal of this final barrier to the advent of 'super-resistant' starter strains will require inputs from sources other than the laboratory bench, and we await developments in these other areas. 


\section{REFERENCES}

Anba J, Bidnenko E, Hillier A, Ehrlich D, Chopin MC (1995) Characterization of the lactococcal abiD1 gene coding for phage abortive infection. $J$ Bacteriol $177,3818-3823$

Beresford TPJ, Ward LJH, Jarvis AW (1993) Temporally regulated transcriptional expression of the genomes of lactococcal bacteriophages $\mathrm{c} 2$ and sk1. Appl Environ Microbiol 59, 3708-3712

Bidnenko E, Ehrlich D, Chopin MC (1995) Phage operon involved in sensitivity to the Lactococcus lactis abortive infection mechanism AbiD1. J Bacteriol 177. 3824-3829

Biswas SK, Chowdury R, Das J (1992) A 14-kilodalton inner membrane protein of Vibrio cholerae biotype el tor confers resistance to group IV choleraphage intection to classical vibrios. J Bacteriol 174, 6221 6229

Budde-Niekiel A, Teuber M (1987) Electron microscopy of the adsorption of bacteriophages to lactic acid streptococci. Milchwissenschaft 42, 551-553

Casey C (1991) Molecular and physical characterization of lysogenic and lytic lactococcal bacteriophages. PhD Thesis. National University of Ireland

Chandry PS, Davidson BE, Hillier AJ (1994) Temporal transcription map of the Lactococcus lactis bacteriophage sk1. Microbiology 140, 2251-2261

Chung DK, Chung SK, Batt CA (1992) Antisense RNA directed against the major capsid protein of Lactococcus lactis subsp cremoris bacteriophage F4-1 confers partial resistance to the host. Appl Microbiol Biotechnol 37, 79-83

Cluzel PJ, Chopin A, Ehrlich SD, Chopin MC (1991) Phage abortive infection mechanism from Lactococcus lactis ssp lactis, expression of which is mediated by an iso-ISS1 element. Appl Environ Microbiol $57,3547-3551$

Coffey AG, Fitzgerald GF, Daly C (1991) Cloning and characterization of the determinant for abortive infection from the lactococcal plasmid pCl829, J Gen Microbiol 143, 1355-1362

Costello V (1988) Characterization of bacteriophagehost interaction in Streptococcus cremoris UC503 and related streptococci. PhD thesis. National University of Ireland

Davis RD, van der Lelie D, Mercenier A, Daly C, Fitzgerald GF (1993) ScrFI restriction-modification system of Lactococcus lactis subsp cremoris UC503: Cloning and characterization of two ScrFI methylase genes. Appl Environ Microbiol 59, 777-785

Duckworth DH, Glenn J, McCorquodale DJ (1981) Inhibition of bacteriophage replication by extrachromosomal genetic elements. Microbiol Rev 45, 52-71

Durmaz E, Higgins DL, Klaenhammer TR (1992) Molecular characterization of a second abortive phage resistance gene present in Lactococcus lactis subsp lactis ME2. J Bacteriol 174, 7463-7469

Duwat $P$, Ehrlich SD, Gruss A (1992) Use of degenerate primers for polymerase chain reaction cloning and sequencing of the Lactococcus lactis ssp lactis recA gene. Appl Environ Microbiol 58, 2674-2678

Duwat P, Gruss A (1994) Characterization of the Lactococcus lactis recA gene and its role in stress response. ASM conference on Streptococcal Genetics, Santa Fe, USA, Abstract 17

Garvey PG (1995) Analysis of three phage resistance mechanisms and a recA homologue encoded by the lactococcal plasmid pNP40. PhD thesis. Dublin City University, Ireland

Garvey PG, Fitzgerald GF, Hill C (1995) Cloning and DNA sequence analysis of two abortive infection phage resistance determinants from the lactococcal plasmid pNP40. Appl Environ Microbiol, 61, 43214328

Garvey PG, Van Sinderen D, Twomey DP, Hill C, Fitzgerald GF (1995) Molecular genetics of bacteriophage and natural phage defense systems in the genus Lactococcus. Int Dairy J 5, 905-947

Geis A, Janzen T, Teuber M, Wirsching F (1992) Mechanism of plasmid-mediated bacteriophage resistance in lactococci. FEMS Microbiol Lett 94, 714

Geller BL, Ivey RG, Trempy JE, Hettinger-Smith B (1993) Cloning of a chromosomal gene required for phage infection of Lactococcus lactis subsp lactis C2. J Bacteriol 175, 5510-5519

Gupta SK, McCorquodale DJ (1988) Nucleotide sequence of a DNA fragment that contains the $a b i$ gene of the Collb plasmid. Plasmid 20, 194-206

Harrington A, Hill C (1991) Construction of a bacteriophage-resistant derivative of Lactococcus lactis ssp lactis $425 \mathrm{~A}$ by using the conjugal plasmid pNP40. Appl Environ Microbiol 57, 3405-3409

Hill C (1993) Bacteriophage and bacteriophage resistance in lactic acid bacteria. FEMS Microbiol Rev $12,87-108$

Hill C, Miller LA, Klaenhammer TR (1990a) Cloning. expression, and sequence determination of a bacteriophage fragment encoding bacteriophage resistance in Lactococcus lactis. J Bacteriol 172, 64196426

Hill C, Miller LA, Klaenhammer TR (1990b) Nucleotide sequence and distribution of the pTR2030 resistance determinant ( $h s p$ ) which aborts bacteriophage infection in lactococci. Appl Environ Microbiol 56, 22552258

Hill C, Massey IJ, Klaenhammer TR (1991a) Rapid method to characterize lactococcal bacteriophage genomes, Appl Environ Microbiol 57, 283-288

Hill C, Miller LA, Klaenhammer TR (1991b) In vivo genetic exchange of a functional domain from a type II methylase between lactococcal plasmid pTR2030 
and a virulent bacteriophage. J Bacteriol 173, 43634370

Josephsen J, Vogensen FK (1989) Identification of three different plasmid-encoded restriction/modification systems in Streptococcus lactis ssp cremoris W56. FEMS Microbiol Lett 59, 161-166

Kelly W, Dobson J, Jorck-Ramberg D, Fitzgerald GF. Daly C (1990) Introduction of bacteriophage resistance plasmids into commercial Lactococcus starter cultures. FEMS Microbiol Rev 87, Abstract P63

Keogh BP (1973) Adsorption, latent period and burst size of phages of some strains of lactic streptococci. J Dairy Res 40, 303--309

Keogh BP, Pettinghill G (1983) Adsorption of bacteriophage eb7 on Streptococcus cremoris EB7. Appl Environ Microbiol 45, 1946-1948

Kim SG, Batt CA (1991) Antisense mRNA-mediated bacteriophage resistance in Lactococcus lactis ssp lactis. Appl Environ Microbiol 57, 1109-1113

Klaenhammer TR, Fitzgerald GF (1994) Bacteriophage and bacteriophage resistance. In: Genetics and Biotechnology of Lactic Acid Bacteria (Gasson MJ, de Vos WM, eds) Blackie Academic and Professional, Chapman and Hall, London, 106-168

Klaenhammer TR, Romero D. Sing WD, Hill C (1991) Molecular analysis of pTR2030 gene systems that confer bacteriophage resistance to lactococci, In: Genetics and Molecular Biology of Streptococci, Lactococci and Enterococci (Dunny GM, Cleary PP, McKay LL, eds) ASM, Washington, DC, 124130

Lucey M (1992) Analysis of the genetic, biochemical and conjugative properties of the bacteriophage resistance plasmid $p C l 528$ from $\mathrm{L}$ lactis ssp cremoris UC503. PhD Thesis. National University of Ireland

Lucey M, Daly C, Fitzgerald GF (1992) Cell surface characteristics of Lactococcus lactis harbouring pCl528, a $46 \mathrm{~kb}$ plasmid encoding inhibition of bacteriophage adsorption. J Gen Microbiol 138, 2137-2143

McKay LL, Baldwin KA (1984) Conjugative 40-megadalton plasmid in Streptococcus lactis subsp diacetylactis DRC3 is associated with resistance to nisin and bacteriophage. Appl Environ Microbiol 47, 6874

McLandsborough LA, Kolaetis KM, Requena T, McKay LL (1995) Cloning and genetic characterization of the abortive infection genetic determinant abiD isolated from $\rho \mathrm{BF} 61$ of Lactococcus lactis subs $\rho$ lactis KR5. App/ Environ Microbiol 61, 2023-2026

Moineau S, Durmaz E, Pandian S, Klaenhammer TR (1992) Differentiation of two abortive mechanisms by using monoclonal antibodies directed towards lactococcal bacteriophage capsid proteins. Appl Environ Microbio/ 59, 208-212

Moineau S, Panthian S, Klaenhammer TR (1994) EvoIution of a lytic bacteriophage via DNA acquisition from the Lactococcus lactis chromosome. Appl Environ Microbiol 60, 1832-1841

Moineau S, Walker SA, Vedamuthu ER, Vandenbergh $P A$ (1995) Cloning and sequencing of Llall restriction/modification genes from Lactococcus lactis and relatedness of this system to the Streptococcus pneumoniae Dpnll system. Appl Environ Microbiol 61, 2193-2202

Monteville MR, Ardestani B, Geller BR (1994) Lactococcal phages require a host cell wall carbohydrate and a plasma membrane protein for adsorption and ejection of DNA. Appl Environ Microbiol 60, 3204 3211

Nauta A, Karsens H, Venema G, Buist G, van Sinderen D (1993) Sequence analysis of a temperate lactococcal bacteriophage. FEMS Microbiol Rev 46, abstract F25

Nyengaard N, Vogensen F, Josephsen J (1993) Llalli, a type II restriction/modifation system from Lactococcus lactis W56. FEMS Microbiol Rev 46, abstract F20

O' Sullivan DJ, Zagula K, Klaenhammer TR (1995) in vivo restriction by $\mathrm{Llal}$ is encoded by three genes, arranged in an operon with LlalM, on the conjugative Lactococcus plasmid pTR2030. J Bacterio/ 177, 134143

Powell IB, Tulloch DL, Hillier AJ, Davidson BE (1992) Phage DNA synthesis and host DNA degradation in the life cycle of Lactococcus lactis bacteriophage c6A. J Gen Microbiol 66, 2737-2741

Sanders ME, Leonhard PJ, Sing WD, Klaenhammer TR (1986) Conjugal strategy for the construction of fastacid producing, bacteriophage-resistant lactic streptococci for use in dairy fermentations. Appl Environ Microbiol 52, 1101-1107

Schafer A, Geis A, Neve H, Teuber M (1991) Bacteriophage receptors of Lactococcus lactis subsp diacetylactis $\mathrm{F} 7 / 2$ and Lactococcus lactis subsp cremoris Wg2-1. FEMS Microbiol Lett 78, 69-74

Schouler C. Ehrlich SD, Chopin M-C (1994) Sequence and organization of the lactococcal prolate-headed blL67 phage genome. Microbiology 140, 3061-3069

Sijtsma L, Jansen N, Hazeleger WC, Wouters JTM, Hellingwerf KJ (1990a) Cell surface characteristics of bacteriophage-resistant Lactococcus lactis ssp cremoris SK110 and its bacteriophage-sensitive variant SK112. Appl Environ Microbiol 56, 32303233

Sijtsma L, Wouters JTM, Hellingwerf KJ (1990b) Isolation and characterization of lipoteichoic acid, a cell envelope component involved in preventing phage adsorption, from Lactococcus lactis ssp cremoris SK110. J Bacteriol 172, 7126-7130

Sing WD, Klaenhammer TR (1990) Characteristics of phage abortion conferred in lactococci by the conjugal plasmid pTR2030. J Gen Microbiol 136, 1807 1815 
Valyasevi R, Sandine WE, Geller BL (1990) The bacteriophage kh receptor of Lactococcus lactis subsp cremoris $\mathrm{KH}$ is the rhamnose of the extracellular wall polysaccharide. Appl Environ Microbiol 56, 18821889

Valyasevi R, Sandine WE, Geller BL (1991) A membrane protein is required for bacteriophage $\mathrm{C} 2$ infection of Lactococcus lactis subsp lactis C2. J Bacteriol 173, 6095-6100
Valyasevi R, Sandine WE, Geller BL (1994) Lactococcus lactis ssp lactis $\mathrm{C} 2$ bacteriophage $\mathrm{sk} 1$ receptor involving rhamnose and glucose moieties in the cell wall. J Dairy Sci 77, 1-6

van de Guchte M, Arendt EK, Horgan J, Healy A, Daly C, Fitzgerald GF (1993) Molecular characterization of the temperate lactococcal bacteriophage Tuc2009. FEMS Microbiol Rev 46, abstract F11 